\title{
Micromorphology and Ultrastructure of the Foot of the Equilateral Venus Gomphina veneriformis (Bivalvia: Veneridae)
}

\author{
Jung Jun Park ${ }^{1}$ Jung Sick Lee ${ }^{2}$, Yeon Gyu Lee ${ }^{3}$, Jae Won Kim ${ }^{4 *}$ \\ ${ }^{1}$ Aquaculture Management Division, NFRDI, Busan, Korea \\ ${ }^{2}$ Department of Aqualife Medicine, Chonnam National University, Yeosu, Korea \\ ${ }^{3}$ Faculty of Marine Technology, Chonnam National University, Yeosu, Korea \\ ${ }^{4}$ Department of Marine Life-Science, Gangwon Provincial College, Gangneung, Korea \\ Email: kjw01@gw.ac.kr
}

Received January 20, 2012; revised March 4, 2012; accepted March 20, 2012

\begin{abstract}
The shape and microscopic structure of the foot of the equilateral Venus, Gomphina veneriformis are described by light and electron microscopy along with the substrate conditions of their habitat. The habitat sediment of G. veneriformis is composed of sand (2 - $0.063 \mathrm{~mm}$ in diameter), mainly. The foot is wedge-shaped with multiple vertical furrows on the surface. Although the foot is composed of an epithelial layer, a connective tissue layer and a muscular layer, the boundary between the connective tissue and muscular layer is not clear. The epithelial layer was composed mostly of ciliated columnar epithelia and secretory cells. Epithelial cells forming the apical region of the fold were long columnar, while cells of the interfold were mostly short columnar. The cilia and microvilli were commonly observed on the free surface of epithelial cells, while tight junctions of apico-lateral aspect and membrane interdigitations were found between the epithelial cells. Secretory cells were found to contain acidic mucopolysaccharide, and were classified into two types in accordance with the shapes and ultrastructures of secretory granules. The muscle fibers were composed of thin and thick microfilaments, the proportions of which were $81.3 \%$ and $18.7 \%$, respectively. It was determined that such morphology and structural characteristics of the foot of $G$. veneriformis would present advantageous conditions for borrowing into substrate and mobility.
\end{abstract}

Keywords: Foot; Gomphina veneriformis; Microscopic Structure

\section{Introduction}

Bivalves are classified into attached and locomotive types in accordance with their mobility, and into epifauna and infauna in accordance with borrowing into sediment [1]. Foot of attached bivalves such as mussel has the capability to attach to substrate by forming byssus thread, while foot of locomotive bivalves such as Mercenaria mercenaria has capabilities including locomotion and burrowing into soft substrate [1,2].

In most infaunal bivalves, the foot is large and wedgeshaped, being adapted for burrowing in soft substrate. It is also laterally flattened, highly muscular and extends nearly the entire ventral surface of the visceral mass [2]. The epithelial cells of bivalve foot expediently respond to various environmental stimuli along with the epithelial cells of mantle and gills [3-6].

As such, information on the structure of these cells could be used in assessing the physiological conditions

${ }^{*}$ Corresponding author. of organisms. In addition, it is also thought that these structural characteristics would differ in accordance with environmental conditions, habitat and taxon [2,7-9].

Gomphina veneriformis is an infaunal bivalve that lives in the sandy subtidal zone within depth range of 1 $20 \mathrm{~m}$, a dominant species in the eastern coastal waters of Korea, and important to the local commercial clam industry $[10,11]$.

However, until now no study has examined the foot ultrastructure of G. veneriformis. This study reports the morphology and ultrastructure of the foot of $G$. veneriformis along with the substrate conditions of their habitat and basic information provided for future studies on foot structural changes induced by environmental factors.

\section{Materials and Methods}

\subsection{Specimens}

Twenty adult G. veneriformis of shell length 35.0 $40.0 \mathrm{~mm}$ were used in this study. The clams were col- 
lected by diving from the shallow $(2-3 \mathrm{~m})$ subtidal zone of Jumoonjin (East Sea of Korea; 37 $54^{\prime} 20.23^{\prime \prime} \mathrm{N}$, $\left.128^{\circ} 49^{\prime} 38.95^{\prime \prime} \mathrm{E}\right)$. Specimens of the foot were prepared by subdividing them into three groups, light microscopy $\left(0.5 \mathrm{~cm}^{3}\right)$, scanning electron microscopy $\left(0.5 \mathrm{~cm}^{3}\right)$, and transmission electron microscopy $\left(2 \mathrm{~mm}^{3}\right)$.

\subsection{Habitat Sediment Analysis}

Grain size analysis of habitat sediments was performed using $10 \mathrm{~g}$ samples taken from experimental sites. Prior to grain size analysis, organic materials and carbonates from the sample were eliminated by adding $10 \%$ hydrogen peroxide $\left(\mathrm{H}_{2} \mathrm{O}_{2}\right)$ and $0.1 \mathrm{~N}$ hydrochloric acid $(\mathrm{HCl})$, sequentially. Subsequently, the samples were put through automatic particle size analyzer (Sedigraph 5100, Micromeritics, USA) and sieve analysis. The weight of each coarse and fine sample is shown by percentage weight at each section [12].

\subsection{Histological analysis}

\subsubsection{Light Microscopy}

Specimen preparation for light microscopy was performed according to the methodology of Drury and Wallington [13]. Specimens were fixed in aqueous Bouin's solution and rinsed in running water and then dehydrated through a graded ethanol series $(70 \%-100 \%)$. The specimens were then embedded in paraplast (McCormick, USA), frozen and subsequently sectioned at $4-6 \mu \mathrm{m}$ thickness using a microtome (RM2235, Leica, Germany). Specimens were stained with Mayer's hematoxylin- $0.5 \%$ eosin (H-E), Masson's trichrome stain, periodic acidSchiff solution and alcian blue (AB-PAS, $\mathrm{pH} 2.5$ ), and aldehyde fuchsin-alcian blue (AF-AB, $\mathrm{pH}$ 2.5) reaction. Stain affinity of mucous cells were determined using the Pantone ${ }^{\circledR}$ formula guide coated first edition 2002 (Pantone Inc. USA) as standard, and its unique code was indicated in parenthesis $[6,14]$.

\subsubsection{Electron Microscopy}

Specimen preparation for electron microscopy was performed according to the methodology of Cormack [15]. Specimens were fixed in $2.5 \%$ glutaraldehyde solution (pH 7.2, buffered 0.1 M phosphate buffer) for $2-4 \mathrm{hrs}$ at $4^{\circ} \mathrm{C}$ and rinsed in $0.1 \mathrm{M}$ phosphate buffer and then postfixed in $1 \%$ osmium tetroxide $\left(\mathrm{O}_{\mathrm{s}} \mathrm{O}_{4}\right)$ solution for $2 \mathrm{hrs}$ at $4^{\circ} \mathrm{C}$. After fixation, the specimens were washed with 0.1 $\mathrm{M}$ phosphate buffer 4 times for $2 \mathrm{hrs}$ and dehydrated with ascending grades of ethanol. Specimens for scanning electron microscope (SEM) were dried with a critical point dryer and the outer surface was coated with gold ion particles (10 $\mathrm{nm}$ in thickness) on an ion sputter (E-1010, Hitachi, Japan). Viewing of samples occurred on the SEM (JSM-7500F, Hitachi, Japan). Specimens for transmission electron microscope (TEM) were embedded in Epon 812, cut at ultrathin sections (70 $\mathrm{nm}$ in thickness) and placed on copper grids (200 mesh) in order to double-stain with uranylacetate and lead citrate. Specimens were examined using a TEM (JEM-1200EXII, JEOL, Japan).

\subsubsection{Image Analysis}

An image analyzer (IMT, Visus, USA) was used to quantify the proportion and thickness of thin and thick microfilaments in the muscle fibers. Ten muscle fibers were analyzed. The total sarcoplasm area under the TEM image, and each of the sums of the areas of thin and thick filaments within the sarcoplasm were measured. After the area of, and ratio between the thin and thick filaments in the cross-section of the sarcoplasm, was calculated, the thickness of thin and thick filaments was computed for the cross-section of ten muscular fibers.

\section{Results}

\subsection{Sediment Composition of Habitat}

The habitat sediment of Gomphina veneriformis is composed of sand (2 - $0.063 \mathrm{~mm}$ in diameter), mainly (Table 1).

\subsection{Foot Morphology and Light Microscopical Structure}

The foot of $G$. veneriformis is wedge-shaped with multiple vertical furrows on the surface and extends nearly the entire ventral surface of the visceral mass (Figure 1).

Table 1. Habitat sediment composition of Gomphina veneriformis.

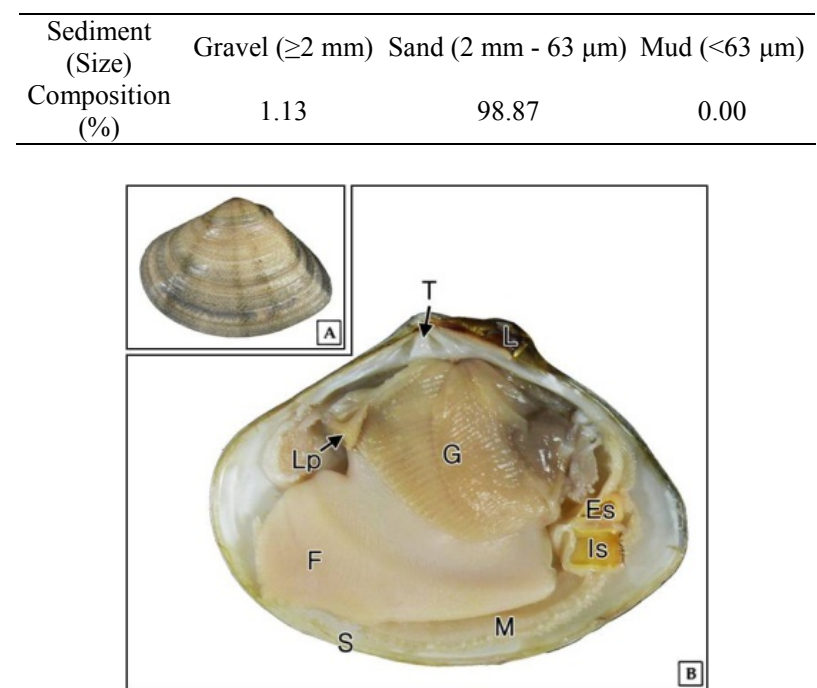

Figure 1. External (A) and internal morphology (B) of Gomphina veneriformis. Es: excurrent siphon; Is: incurrent siphon; G: gill; F: foot; L: ligament; Lp: labial palp; M: mantle; S: shell; T: tooth. 
Histological analysis revealed that it is composed of an epithelial layer, connective tissue layer and a muscular layer. While the epithelial layer has definitive boundary, the boundary between the connective tissue layer and the muscular layer is not clear (Figures 2(A) and (B)).

Foot surface was folded multiple times, while the epithelial layer was mostly composed of ciliated columnar epithelia and mucous cells. The epithelial layer thickness was approximately $15 \mu \mathrm{m}$ on the ventral side, while a well-developed striated border was formed on the free surface. The epithelium shape differed depending on its position. Epithelial cells forming the apical region of the fold were long columnar, while cells of the interfold were mostly short columnar (Figure 2(C)).

Mucous cells were observed in both epithelial and muscular layers, with vacuolar form in H-E and Masson's triple stains (Figures 2(A)-(C)). Distribution of mucous cells was found to be higher in the anterior and posterior tip than those in the ventral region (Figures 2(D) and (E)). AB-PAS ( $\mathrm{pH} 2.5)$ reaction revealed two types of mucous cells; where one type reacted with a red color (496C) and the other responded to a blue color (542C). Higher numbers of blue-colored mucous cells were observed in the ventral region (Figure 2(D)). In the anterior tip, mucous cells displayed a blue color due to reaction with alcian blue (Figure 2(E)). Mucous cells also displayed a blue color $(7464 \mathrm{C})$ in the results of the $\mathrm{AF}-\mathrm{AB}(\mathrm{pH} 2.5)$ reaction (Figure 2(F)).

The connective tissue layer appeared very thin (Figure 2(F)), was loose, and composed of mainly collagen fibers (Figure 2(A)). The muscular layer was composed of collagen fibers and muscular fiber bundles, with presence of hemolymph sinus. The muscular fiber bundle was distributed regularly in both horizontal and vertical directions (Figures 2(A)-(F)).

\subsection{Electron Microscopical Structure}

SEM observation showed that the foot surface was covered with ciliary tufts (Figure 3(A)). However, the density of cilia was not uniform across the fold area. Cilia density was higher in the apical region of the fold compared to the interfold region (Figure 3(B)).

TEM observation revealed that the epithelial layer is composed of ciliated columnar epithelia and secretory cells.

Ciliated columnar epithelial cells in apical region of the fold have well-developed cilia and microvilli on the free surface. Length of these cells was approximately 16 $\mu \mathrm{m}$, while the cilia length was approximately $8 \mu \mathrm{m}$. Tight junctions of the apico-lateral aspect and membrane interdigitations were found between epithelial cells. The nucleus was oval shaped and located in the middle or basal portion of the cell (Figure 4(A)). Also, epithelial cells in lateral and basal regions of the fold have well-developed cilia and microvilli on the free surface. These cells have irregular oval shaped nucleus in the basal cytoplasm and heterochromatins with high electron density are distributed near the nuclear membrane (Figures 4(B) and (C)).

In the basal epithelial cells of the fold, tubular mitochondria appear clustered in the apical cytoplasm (Figure $4(C)$ ) and have connected ciliary rootlets (Figure 4(D)). Cross section of cilia showed " $9+2$ " microtubular structure (Figure 4(E)).
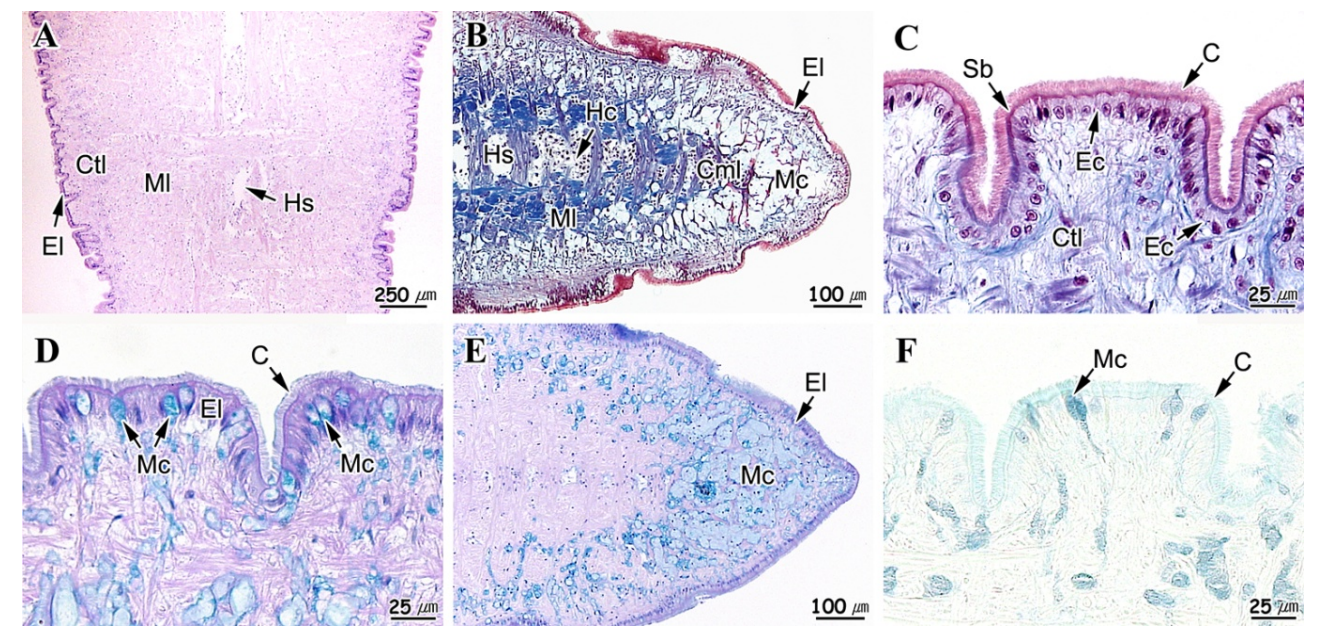

Figure 2. Light microscopical feature of the foot of Gomphina veneriformis. (A) Sagittal section showing the epithelial layer (El), connective tissue layer (Ctl) and muscle layer (Ml). H-E stain; (B) Section of anterior tip. Masson's trichrome stain; (C) Epithelial layer, showing the simple ciliated columnar epithelium (Ec). Masson's trichrome stain; (D) Epithelial layer of ventral region, showing the mucous cell (Mc) of alcian blue positive. AB-PAS (pH 2.5) reaction; (E) Anterior tip, showing the numerous mucous cell of alcian blue positive in the connective tissue layer. AB-PAS (pH 2.5); (F) Epithelial layer of ventral region, showing the mucous cell (Mc) of alcian blue positive. AF-AB (pH 2.5) reaction. C: cilia; Cfb: collagen fiber bundles; Cml: circular muscle layer; Hc: hemocyte; Hs: hemolymph sinus; Lml: longitudinal muscle layer; Sb: striated border. 


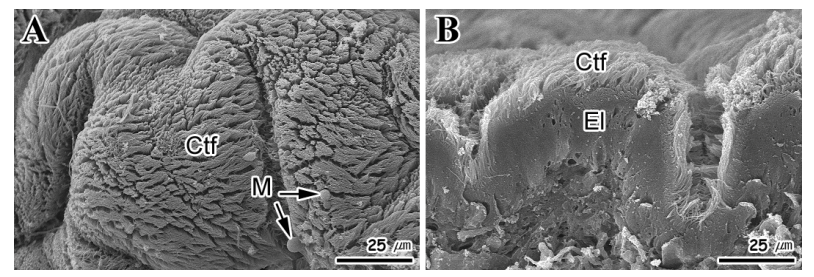

Figure 3. Scanning electron micrographs of the foot surface of Gomphina Veneriformis. (A) Frontal view showing the numerous folds and ciliary tuft (Ctf); (B) Cross section showing the developed ciliary tuft on epithelial layer (EI). M: mucous.

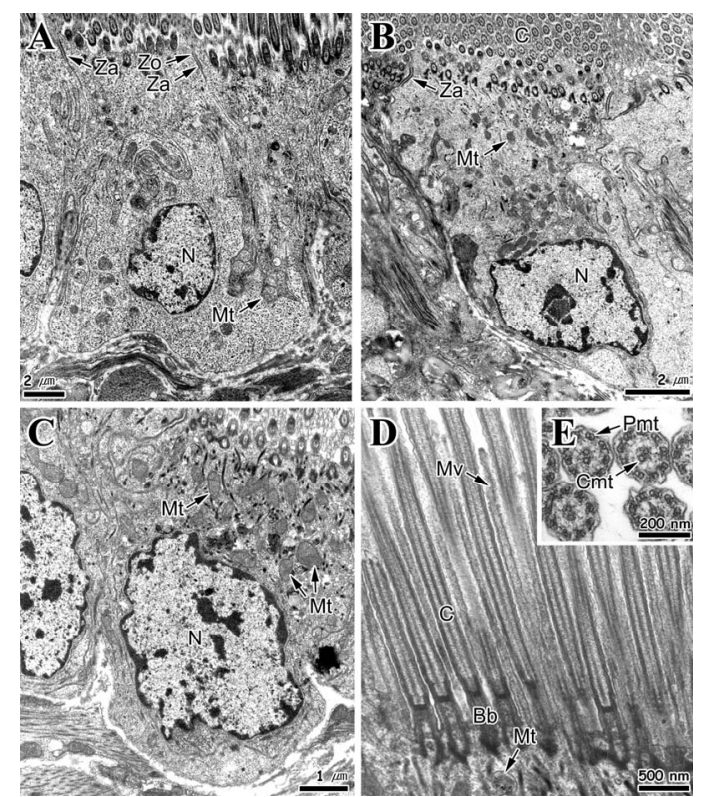

Figure 4. Transmission electron micrographs of the foot epithelial layer of Gomphina veneriformis. (A) Section of long ciliated columnar epithelial cell in apical region of the fold showing the cilia and zonular occuludens (Zo) and zonular adherens (Za) in the apico-lateral cytoplasm; (B) Ciliated columnar epithelial cell in lateral region of the fold; (C) Section of short ciliated epithelial cell of basal region of the fold showing the numerous mitochondria (Mt) in the apical cytoplasm; (D) Longitudinal section of cilia (C) on the free surface of the epithelial cell. Note the basal body (Bb) and rootlet complex connected with mitochondria; (E) Cross section of cilia showing the $9+2$ arrangement. Cmt: central microtubule; Mv: microvilli; N: nucleus; Pmt: peripheral microtubule.

Secretory cells are unicellular glands and can be divided into two types (A and B) depending on cell shape and characteristics of secretory granules. Type A secretory cells are circular and develop from the epithelial layer to the connective tissue layer. The cytoplasm was filled with secretory granules of low electron density (Figure 5(A)). The distribution of these cells was lower than the type B secretory cells. Type B secretory cells exist mainly in the connective tissue and muscular layer, exhibit a typical goblet form and have a length of ap- proximately $8 \mu \mathrm{m}$. These cells have secretory granules with granular materials, the electron density of which was higher than those of type B secretory cells. Furthermore, numerous rough endoplasmic reticula and Golgi complex were found in the basal cytoplasm of these cells (Figure 5(B)).

Muscle fibers and some collagen fibers were observed in the muscular layer. The type of muscle fiber was mostly smooth, while tubular mitochondria and small number of sarcoplasmic reticula were observed in the cortical sarcoplasm (Figure 5(C)). The muscle fibers were composed of thin and thick microfilaments. The diameter of thin filament was approximately $5 \mathrm{~nm}(2.5-$ $7.8 \mathrm{~nm})$ while that of thick filament was $52 \mathrm{~nm}(34-81$ $\mathrm{nm})$ (Figures 5(C) and (D)). The proportions of thin and thick microfilaments within muscle fibers were $81.3 \%$ and $18.7 \%$, respectively. In the longitudinal section, some transverse striations of high electron density were identified in the collagen fibers (Figure 5(D)).

\section{Discussion}

The shape of bivalve foot differ greatly depending on the habit conditions. Foot of attached bivalves is simple and degenerated [1]. However, the foot shape of Mercenaria mercenaria (Veneridae), which is a borrowing bivalve,

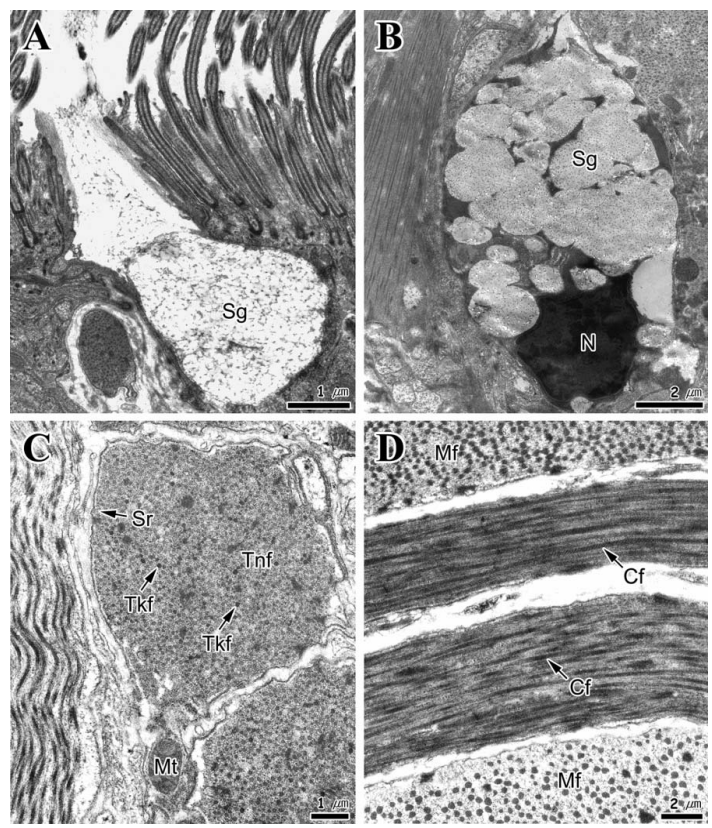

Figure 5. Transmission electron micrographs of the foot of Gomphina veneriformis. (A) Type A secretory cell. Note the secretory granules (Sg) of low electron density with fibrous materials; (B) Type B secretory cell. Note the secretory granules of high electron density with granular materials; (C) Cross section of muscle fibers showing the thin (Tnf) and thick filaments (Tkf); (D) Longitudinal section of collagen fibers (Cf). Mf: muscle fiber; Mt: mitochondrion; $N$ : nucleus; Sr: sarcoplasmic reticulum. 
is in wedge shaped, has multiple vertical furrows on the surface and contains mucous cells in the epithelial layer [2]. In this study, the foot of Gomphina veneriformis also displayed similar shapes and structural characteristics. It was determined that such characteristics would present advantageous conditions for borrowing into substrate.

Histological analysis of bivalve foot have revealed that it is composed of an epithelial layer, which is simple and composed of columnar epithelial cells and secretory cells, a connective tissue layer, which is relatively thin, and a muscular layer, which is composed mainly of collagen fibers and smooth muscle fibers [2]. Analysis of M. mercenaria foot revealed that it is covered with simple columnar epithelia that are ciliated near the tip of the anterior extremity, while the crests of folds are tall columnar and troughs are low columnar [2].

This general structure was confirmed here, where the foot of $G$. veneriformis was shown to possess an epithelial layer, connective tissue layer, and a muscular layer. Our analysis also revealed that the foot epithelial layer of $G$. veneriformis was similar to M. mercenaria [2].

Ciliated columnar epithelium in bivalves has also been reported in Solemya reidi [16] and M. mercenaria [2]. These ciliated cells contained numerous tubular mitochondria in their apical cytoplasm. The function of cilia on free surface of the epidermis is related to discharging of foreign materials entering the mantle cavity, in addition to moving mucous substances outside of the mantle cavity $[3,17]$. In this study foot ciliated cell of $G$. veneriformis contained numerous mitochondria in the apical cytoplasm.

Functions of foot gland have been determined to be habitat-specific. In the case of burrowing bivalves, it is mainly used for borrowing into sediments, while in the case of attached bivalves it appears to be associated with formation of attaching apparatus. Mya arenaria, a burrowing bivalve, has two types of glands in its pedal aperture; bacillary mucous cells and mucous goblet cells. Bacillary mucous cells secrete glycoprotein as the principal type, and mucous goblet cells secrete sulfated and nonsulfated mucosubstances. Their main functions are associated with pseudofeces formation and burrow into sediments [8].

The characteristics of mucous secreted by the gland cells have been reported to be species-specific [18]. Foot mucous cells of $M$. mercenaria were reported to contain acid glycosaminoglycans rich in sulfate and carboxylate groups [2].

AB-PAS ( $\mathrm{pH} 2.5)$ reaction in this study confirmed that mucous cells contained mainly acidic mucopolysaccharides. This study confirmed that mucous cells contained acidic material abundant in carboxylate group from the results of AF-AB ( $\mathrm{pH} 2.5$ ) reactions.

G. veneriformis, like M. arenaria and M. mercenaria, is a burrowing bivalve. Therefore, mucous secreted from their foot are deemed to function in formation of pseudofeces, purification of mantle cavity [6], and burrowing into sediments along with mucous secreted from the mantle.

In general, exocrine glands are classified into unicellular and multicellular glands according to the number of composition cells, and can be divided further into holocrine glands and merocrine glands depending on their patterns of secretion [19]. Based on these standards, all secretory cells reported in S. reidi [14], M. mercenaria (Eble, 2001) and Scapharca broughtonii [4] were unicellular glands.

It was presumed that these were merocrine glands, as cell death and cellular components were not observed in the lumen. This study also revealed two types of secretory cells in the foot of $G$. veneriformis, both of which are unicellular and merocrine glands.

The muscular cells of invertebrates can be divided into three major classes on the basis of their striation pattern; transversely striated, obliquely striated, or smooth muscle. Invertebrate smooth muscle differs from that of vertebrates, principally in the higher proportion and larger diameter of thick myofilaments [20].

Smooth muscle cells can be categorized into four types (A, B, C and D) in accordance with characteristics of 1) the diameter of the thick myofilament, 2) density of an arrangement of dense bodies, 3 ) the size of the cell, and 4) other characteristics (structure of sarcoplasmic reticulum system, mitochondria, etc.) [21].

Among theses, the diameter of thick myofilament in C-type is $60-120 \mathrm{~nm}$ with small number of large sized dense bodies. The size of sarcoplasmic reticulum is small and distributed at periphery. This type of muscle cells in bivalves can be found in the adductor of Atrina, Astarte and Meretrix [21].

In this study, the foot muscle fiber of $G$. veneriformis is determined to be the C-type in accordance with distribution of thin and thick filaments, thickness of thick filaments, and size and location of sarcoplasmic reticulum and mitochondria.

Thin and thick filaments are irregularly mixed in foot muscle fibers of $G$. veneriformis. The diameter of thin filament was approximately $5 \mathrm{~nm}(2.5-7.8 \mathrm{~nm})$ while that of thick filament was $52 \mathrm{~nm}(34-81 \mathrm{~nm})$.

Muscle fibers in the translucent part of the adductor of Crassostrea angulata contained thick and thinner filaments [22]. The opaque portion in the adductor of Chlamys nobilis was composed of smooth muscle cells that contained thin and thick filaments. The thick filaments were classified into two kinds; thinner and shorter filaments, and thicker and longer ones. The thinner and shorter filaments were about $26.5 \mathrm{~nm}$ in diameter and 7.5 $\mu \mathrm{m}$ in length, and the thicker and longer ones were about 
$42.0 \mathrm{~nm}$ in diameter and $13.0 \mu \mathrm{m}$ in length, respectively [23].

\section{Acknowledgements}

This research was supported by Basic Science Research Program through the National Research Foundation of Korea (NRF) funded by the Ministry of Education, Science and Technology (2012-0004670).

\section{REFERENCES}

[1] E. Gosling, "Bivalve Molluscs: Biology, Ecology and Culture," Blackwell Science, Oxford, 2004.

[2] A. F. Eble, "Anatomy and Histology of Mercenaria mercenaria," In: J. N. Kraeuter and M. Castagna, Eds., Biology of the Hard Clam, Elsevier, New York, 2001, pp. 117-220.

[3] J. Machin, "Role of Integument in Molluscs," In: B. L. Gupta, R. B. Moreton, J. L. Oschman and B. J. Wall, Eds., Transport of Ions and Water in Animals, Academic Press, New York, 1977, pp. 735-762.

[4] J. S. Lee, "Ultrastructure of the Mantle Epidermis in the Ark Shell Scapharca broughtonii (Bivalvia: Arcidae)," Korean Journal of Electron Microscopy, Vol. 32, 2002, pp. 213-222.

[5] S. M. Ju, J. W. Lee, Y. G. Jin, J. Yu and J. S. Lee, "Effect of Zinc Bioaccumulation on Survival Rate, Activity, Growth and Organ Structure of the Equilateral Venus, Gomphina veneriformis (Bivalvia: Veneridae)," Journal of Environmental Toxicology, Vol. 21, 2006, pp. 115-126.

[6] J. S. Lee, J. Y. Joo and J. J. Park, "Histology and Ultrastructure of the mantle epidermis of Gomphina veneriformis (Bivalvia: Veneridae)," Journal of Shellfish Research, Vol. 26, No. 2, 2007, pp. 413-421. doi:10.2983/0730-8000(2007)26[413:HAUOTM]2.0.CO; $\underline{2}$

[7] L. Vitellaro-Zuccarello, "Ultrastructural and Cytochemical Study on the Enzyme Gland of the Foot of a Mollusk," Tissue and Cell, Vol. 13, No. 4, 1981, pp. 701-713. doi:10.1016/S0040-8166(81)80007-9

[8] J. L. Norenburg and J. D. Ferraris, "Cytomorphology of the Pedal Aperture Glands of Mya arenaria L. (Mollusca, Bivalvia)," Canadian Journal of Zoology, Vol. 68, No. 6, 1990, pp. 1137-1144. doi:10.1139/z90-169

[9] A. Garcia-Gasca, R. I. Ochoa-Baez and M. Betancourt, "Microscopic Anatomy of the Pearl Oyster Pinctada mazatlanica (Hanley, 1856)," Journal of Shellfish Research, Vol. 13, 1994, pp. 85-91.

[10] J.-S. Yoo, “Korean Shells in Color," Iljisa Publishing Co.,
Seoul, 1988.

[11] S. Y. Hong, "Marine Invertebrates in Korean Coasts," Academy Publishing Company, Inc., Seoul, 2006.

[12] R. L. Folk, "Petrology of the Sedimentary Rocks,"Austin, Texas, 1968.

[13] R. A. B. Drury and E. A. Wallington, "Carleton's Histological Technique," Oxford University Press, Oxford, 1980.

[14] P. G. Beninger, S. St-Jean, Y. Poussart and J. E. Ward, "Gill Function and Mucocyte Distribution in Placopecten magellanicus and Mytilus edulis (Mollusca: Bivalvia): The Role of Mucus in Particle Transport," Marine Ecological Progress Series, Vol. 98, 1993, pp. 275-282. doi: $10.3354 /$ meps098275

[15] D. H. Cormack, "Introduction to Histology," In: Essential Histology, 2nd Edition, Lippincott Williams \& Wilkins, Philadelphia, 2001, pp. 1-23.

[16] R. G. Gustafson and R. G. B. Reid, "Larval and PostLarval Morphogenesis in the Gutless Protobranch Bivalve Solemya reidi (Cryptodonta: Solemyidae)," Marine Biology, Vol. 97, No. 3, 1988, pp. 373-387. doi:10.1007/BF00397768

[17] P. S. Galtsoff, "The American Oyster Crassostrea virginica Gmelin. Fishery Bulletin of the Fish and Wildlife Service," United States Government Printing Office, Washington DC, 1964.

[18] M. S. Davies and J. Hawkins, "Mucus from Marine Mollusks," Advance in Marine Biology, Vol. 34, 1998, pp. 1-71. doi:10.1016/S0065-2881(08)60210-2

[19] K. Kurosumi, S. Shibasaki and T. Ito, "Cytology of the Secretion in Mammalian Sweat Glands," International Review of Cytology, Vol. 87, 1984, pp. 253-329. doi:10.1016/S0074-7696(08)62445-6

[20] R. Paniagua, M. Royuela, R. M. Garcia-Anchuelo and B. Fraile, "Ultrastructure of Invertebrate Muscle Cell Type," Histology and Histopathology, Vol. 11, 1996, pp. 181201.

[21] A. Matsuno, "Ultrastructural Classification of Smooth Muscle Cells in Invertebrates and Vertebrates," Zoological Science, Vol. 4, No. 1, 1987, pp. 15-22.

[22] J. Hanson and L. Lowy, "The Structure of the Muscle Fibers in the Translucent Part of the Adductor of the Oyster Crassostrea angulata," Proceedings of the Royal Society B, Vol. 154, No. 955, 1961, pp. 173-196. doi:10.1098/rspb.1961.0027

[23] A. Matsuno, H. Ishida and H. Hori, "Two Kinds of Thick Filament in Smooth Muscle Cells in the Adductor of a Clam, Chlamys nobilis," Tissue and Cell, Vol. 25, No. 3, 1993, pp. 325-332. doi:10.1016/0040-8166(93)90074-U 